Mens

revue d'histoire intellectuelle de l'Amérique française

\title{
Une lettre d'Henri Bourassa à Roland Provost (26 mars 1935)
}

\section{Damien-Claude Bélanger}

Volume 1, numéro 1, automne 2000

URI : https://id.erudit.org/iderudit/1024440ar

DOI : https://doi.org/10.7202/1024440ar

Aller au sommaire du numéro

Éditeur(s)

Centre de recherche en civilisation canadienne-française

ISSN

1492-8647 (imprimé)

1927-9299 (numérique)

Découvrir la revue

Citer ce document

Bélanger, D.-C. (2000). Une lettre d'Henri Bourassa à Roland Provost (26 mars 1935). Mens, 1(1), 69-74. https://doi.org/10.7202/1024440ar d'utilisation que vous pouvez consulter en ligne.

https://apropos.erudit.org/fr/usagers/politique-dutilisation/ 


\section{INÉDIT ${ }^{1}$}

Une lettre d'Henri Bourassa²

à Roland Provost ${ }^{3}$

(26 mars 1935)

\section{Édition critique établie par \\ Damien-Claude Bélanger}

\section{PRÉSENTATION}

Cette lettre d'Henri Bourassa est tirée du Fonds Lionel-Groulx des Archives du Centre de recherche Lionel-Groulx. Il s'agit d'une réponse à une missive que lui avait envoyée Roland Provost. Ce dernier l'a remise à Groulx entre la fin de mars et le milieu du mois de mai $1935^{5}$. Elle contient deux sections bien distinctes. Dans un premier temps, Bourassa fait une analyse des dangers moraux de (d'idolâtrie» et met le jeune Provost en garde contre le culte de la personnalité. Provost avait écrit à Bourassa pour lui affirmer que Groulx «est un de vos disciples et qu'il a pour vous justement la vénération d'un disciple pour le Maitre. Et comme les maitres de nos maitres sont nos maitres, [vous êtes] aussi pour moi le chef" $"$.

La mise en garde de Bourassa est fort significative. En fait, elle témoigne de la distance intellectuelle qui sépare Bourassa de l'abbé Groulx au cours des années 1920 et 1930 . Observant la renaissance nationaliste qui s'opère sous l'égide de chefs charismatiques dans plusieurs pays catholiques d'Europe durant la Crise, notamment en Irlande, en Italie et au Portugal, Groulx souhaite l'avènement d'un tel chef au Canada français ${ }^{7}$. Bourassa, pour sa part, n'y voit qu'une porte ouverte au nationalisme outrancier. D'ailleurs, à cette époque, Bourassa accuse Groulx et ses disciples d'être les principaux propagateurs canadiens-français de cette tendance nationaliste condamnée par le pape Pie $\mathrm{XI}$. Voilà probablement pourquoi il réagit aussi fortement dans sa lettre contre l'admiration que vouait le jeune Provost à l'abbé Groulx.

Dans la deuxième section de sa lettre, Bourassa dresse un portrait de l'action politique d'Armand La Vergne ${ }^{8}$. Ce paragraphe offre une explication du silence que s'était imposé Bourassa à la suite du décès de La Vergne, survenu le 5 mars $1935^{\circ}$. Il s'agit également d'un témoignage éloquent sur les querelles intestines qui ont marqué l'action politique du mouvement nationaliste des premières décennies du XX ${ }^{e}$ siècle. Mû par le désir de dépasser la lutte des partis, ce mouvement manquait de cohésion interne et fut éventuellement largement récupéré par les deux partis traditionnels. Le cheminement politique de La Vergne suit de près cette évolution. Député anti-impérialiste de la Ligue nationaliste avant la Première Guerre mondiale, il finira par se rallier au Parti conservateur de Bennett. 


\title{
Chambre des Communes
}

Canada

Ottawa, 26 mars 1935.

\author{
M. Roland Provost, \\ 4027 Harvard, \\ MONTRÉAL. ${ }^{10}$
}

Monsieur,

De retour de Montréal hier soir, je m'empresse de répondre à votre lettre du 21.

Les sentiments d'admiration que vous manifestez à mon endroit me touchent profondément. Mais permettez-moi de vous mettre en garde contre cette tendance trop générale chez nous ${ }^{11}$ - tendance héritée de nos ancêtres de France et accrue par l'état de demi-sauvagerie où nous avons vécu pendant près de deux siècles. L'idolâtrie, même quand elle ne porte pas atteinte aux droits de Dieu, est toujours un mal. Dans l'ordre des choses humaines, comme dans l'ordre divin, les hommes ont besoin d'être éclairés, guidés et gouvernés. Mais, en tout ce qui touche à leurs affaires temporelles, le privilège de l'infaillibilité n'est donné à personne. Les hommes et les nations ont le devoir d'obéir aux autorités constituées; ils ont aussi celui de n'accorder leur confiance qu'aux guides les plus sûrs, qui les conduisent dans la voie du devoir, et non pas à ceux qui, sincèrement ou non, flattent leurs passions ou leur vanité de race, de classe etc. ${ }^{12}$ Malheureusement, c'est ceux-ci que les Canadiens français ${ }^{13}$ suivent le plus volontiers et le plus aveuglément. Depuis un siècle ils ont dressé des piédestaux à une foule d'hommes plus ou moins dignes de leur confiance, quitte à changer d'idole suivant leur passion du moment. Quand je menais la lutte contre M. Laurier ${ }^{14}$, pour la défense de principes qui me paraissaient supérieurs à toute considération d'amitié ou d'admiration pour un homme, quelque éminent qu'il fût, je ne perdais aucune occasion de mettre mes compatriotes en garde contre cette tendance idolâtrique. J'ai même parfois froissé certains de mes amis en repoussant les hommages exagérés qu'ils m'offraient.

Voilà pour la thèse générale. Un mot maintenant de $\mathrm{M}$. La Vergne $^{15}$. D'abord, vous êtes dans l'erreur lorsque vous voyez en lui l'un de mes «disciples de la première heure». Depuis plusieurs années déjà, je menais la campagne contre l'impérialisme anglais et la complaisance de nos chefs politiques à cet égard, lorsque Armand La Vergne 
s'est fait élire pour la première fois, comme candidat libéral. Notez cette dernière circonstance : dès ce moment je signalai à La Vergne l'incompatibilité de l'indépendance politique qu'il réclamait et de l'appui personnel et pécuniaire qu'il acceptait du parti libéral. A Ottawa comme à Québec, La Vergne a soutenu de belles luttes, il a pris quelques initiatives méritoires quoique secondaires ${ }^{16}$; mais il n'a jamais voulu ou su prendre les moyens de sauvegarder sa pleine indépendance. C'est ce qui l'a fait passer définitivement sous les fourches caudines du parti conservateur. Rappelez-vous qu'il est devenu le candidat et l'homme lige de Meighen ${ }^{17}$, le principal protagoniste de la guerre à outrance, de la banqueroute du Canada pour le salut de l'Empire, de la conscription, et, finalement, du rapprochement politique avec la Russie des Soviets, que La Vergne a plus tard dénoncé avec plus d'éclat que de raisonnement. Du jour où il s'est incorporé au parti tory, malgré mes objurgations, $j$ 'ai dû cesser toute relation politique avec lui, tout en lui conservant un vif sentiment d'amitié et de commisération. A mes yeux, ses qualités de cœur, et aussi les lacunes de son esprit et de son éducation ${ }^{18}$, atténuent largement ses erreurs de jugement et de conduite. Aussi, suisje persuadé que Dieu l'a jugé très miséricordieusement. Tout au long de sa dernière maladie et depuis sa mort, je n'ai cessé de prier et de faire prier pour lui. Mais s'il s'agissait d'apprécier son rôle d'homme public, il me faudrait faire des réserves très graves. Ce serait cruel pour sa mémoire et pour ses amis. Entre les exigences de l'amitié et celles de la vérité qu'on ne doit jamais sacrifier, j’ai cru devoir garder le silence.

Veuillez agréer, Monsieur, l'assurance de ma sincère considération.

Henri Bourassa

$\mathrm{HB} / \mathrm{CG}$

\section{NOTES}

${ }^{1}$ Nous tenons à remercier le Père Roland Provost pour l'aide précieuse qu'il a apportée à la rédaction de cette édition critique.

${ }^{2}$ Henri Bourassa (1868-1952). Journaliste, homme politique et intellectuel nationaliste, né à Montréal. Maire de Montebello, Québec (1890); rédacteur en chef et propriétaire de L'Interprète de Clarence Creek, Ontario (1892-1895); premier maire de Papineauville (1896-1898); député libéral du comté de Labelle à la Chambre des Communes (1896-1899); secrétaire de la Commission anglo-américaine de Québec (1898) et de Washington (1899). Incapable d'accepter la politique du gouvernement Laurier à l'égard de la participation canadienne à la guerre sud-africaine, il démissionne en 1899, puis se fait réélire lors d'une élection partielle en 1900 . Il siège alors comme 
libéral indépendant jusqu'en 1907. Défait lors d'une élection provinciale partielle dans la circonscription de Bellechasse (1907), il est élu député nationaliste du comté provincial de Saint-Hyacinthe aux élections générales de 1908, poste qu'il occupera jusqu'en 1912. Fondateur et premier directeur du quotidien Le Devoir (1910-1932), il fera un retour dans l'arène fédérale en 1925 et représentera de nouveau les électeurs du comté de Labelle, cette fois en tant que député libéral indépendant, jusqu'à sa défaite aux élections générales de 1935. Journaliste prolifique, Henri Bourassa fut le principal représentant du nationalisme canadien-français avant la mutation intellectuelle et identitaire que connait ce mouvement au cours des années 1920, sous l'impulsion de l'abbé Lionel Groulx et de la revue L'Action française de Montréal.

${ }^{3}$ Roland Provost (1914- ). Prêtre, historien et archéologue, né à Montréal. Études classiques au Collège de Montréal (1927-1936). Religieux de Sainte-Croix, ordonné le 24 septembre 1939. Professeur d'histoire à l'Université St-Joseph de Memramcook, N.-B. (1941-1948); missionnaire auprès des Micmacs de Maria dans le diocèse de Gaspé (1951-1963). Quittant la Congrégation de Sainte-Croix en 1953, il est nommé curé des paroisses du Sacré-Cœur des Landes et de Saint-Bernard-des-Lacs (diocèse de Gaspé), en 1960. Après trois ans d'études archéologiques à la Sorbonne, il est co-fondateur, en 1970, de la Société d'histoire et d'archéologie des Monts (Ste-Anne-des-Monts, Qc.).

${ }^{4}$ Lettre d'Henri Bourassa à Roland Provost, Ottawa, 26 mars 1935, 3 p. $(21,6 \mathrm{~cm} \times 28$ $\mathrm{cm})$. En-tête officiel de la Chambre des Communes sur la p. 1. Dactylographiée avec corrections et signature autographes. Archives du Centre de recherche Lionel-Groulx (ACRLG), 261 rue Bloomfield, Outremont, Fonds Lionel-Groulx (FLG), cote B 2, 99. Réponse à la lettre de Roland Provost, Montréal, 21 mars 1935, attestée par la présente missive et par une copie du brouillon conservée dans le dossier Roland Provost du Centre de recherche Lionel-Groulx.

${ }^{5}$ Dans une lettre subséquente à Provost, Groulx, qui ne partageait ni la ferveur pancanadianiste de Bourassa, ni son jugement plutôt sévère sur la carrière politique d'Armand La Vergne (voir à ce sujet : Lionel Groulx, Mes mémoires, tome 3, Montréal, Fides, 1972, pp. 183-200), souligne que la missive de Bourassa «appellerait des commentaires que je vous ferai de vive voix, un jour ou l'autre. Que la vie vous apprenne à juger les hommes sur l'ensemble et par les dominantes et à beaucoup pardonner à la faiblesse humaine.» [Lettre de Lionel Groulx à Roland Provost, Montréal, $21 \mathrm{mai}$ 1935, 1 f. (2 p.) ms. : 1-2. ACRLG, FLG, cote P1/A, 3101.]

${ }^{\circ}$ Lettre de Roland Provost à Henri Bourassa, Montréal, [21] mars 1935. Copie conservée dans le dossier Roland Provost du CRLG.

' Il est important de souligner que Groulx partageait néanmoins le jugement de Bourassa à l'égard du culte que vouaient bien des Canadiens français à Wilfrid Laurier. D'ailleurs, en 1962, il soulignera à Raymond Barbeau qu'une des grandes contributions de Bourassa à sa nation aura été de la délivrer de sl'idôlatrie [sic] lauriériste». [Lettre de Lionel Groulx à Raymond Barbeau, Outremont, 4 janvier 1962, 2 p. dact. : 1. ACRLG, FLG, cote P1/A, 154.]

${ }^{8}$ Armand La Vergne (1880-1935). Avocat, journaliste et homme politique né à Arthabaska. Membre fondateur de la Ligue nationaliste canadienne (1903); député libéral du comté de Montmagny à la Chambre des Communes (1904-1908); à l'Assemblée législative de Québec, membre fondateur et député de la Ligue nationaliste pour 
le comté de Montmagny (1908-1916); organisateur pour les conservateurs-nationalistes du Québec durant l'élection fédérale de 1911. Candidat indépendant défait dans l'élection fédérale de 1917, il le sera également sous la bannière conservatrice lors des scrutins fédéraux de 1921, 1925 et 1926. Élu député fédéral conservateur du comté de Montmagny lors de la victoire de R.B. Bennett aux élections de 1930, il sera viceprésident de la Chambre des Communes en 1930, et y siégera jusqu’à sa mort en 1935. Journaliste et homme politique combatif, La Vergne chérira son indépendance d'esprit et son nationalisme en dépit de ses attaches partisanes. Auteur de Trente ans de vie nationale (mémoires), Montréal, les Éditions du Zodiaque, 1934, 228 p.

' Dans sa lettre à Bourassa, Provost affirmait avoir été «étonné de constater que le chef [Bourassa] n'avait pas donné sa pensée, ses souvenirs [mêmes] à la mort d'un de ses disciples de la première heure m. [Provost à Bourassa, 26 mars 1935, loc. cit.]

${ }^{10}$ Écrit : MONTREAL

${ }^{11}$ Écrit : chez-nous

12 Écrit : etc.. [avec deux points]

${ }^{13}$ Écrit : Canadiens-français

${ }^{14}$ Wilfrid Laurier (1841-1919). Avocat, journaliste et Premier ministre du Canada, né à St-Lin, Canada-Est. Brièvement rédacteur en chef du journal Le Défricheur d'Arthabaskaville; député libéral de Drummond-Arthabaska à l'Assemblée législative de Québec (1871-1874); à la Chambre des Communes : député libéral du comté de Drummond-Arthabaska (1874-1877); de Québec-Est (1877-1919); ministre du Revenu dans le cabinet Mackenzie (1877-1878); chef du Parti libéral du Canada (18871919); chef de l'opposition à la Chambre des Communes (1887-1896); Premier ministre du Canada et président du Conseil privé (1896-1911); nommé membre du Conseil privé de l'Empire britannique (1897); représentant canadien aux conférences impériales de 1902, 1907 et 1911. Mentor du jeune Henri Bourassa, Laurier fut le premier Canadien français à diriger le Canada. Son administration présida à une période d'expansion démographique et économique sans précédent pour le jeune Dominion.

${ }^{15}$ Écrit tout au long du texte : LaVergne [en un mot]

${ }^{16}$ Ici, Bourassa fait probablement allusion à la fameuse «Loi La Vergne» adoptée par l'Assemblée législative de Québec en 1910. Difficile à faire respecter, cette loi rendait le bilinguisme obligatoire pour les compagnies de chemin de fer, de téléphone, de télégraphe, de tramway, de navigation et d'électricité dans leurs communications avec le public québécois.

${ }^{17}$ Arthur Meighen (1874-1960). Avocat, homme d'affaires, sénateur et Premier ministre du Canada, né à Anderson, Ontario. Député conservateur puis unioniste du comté de Portage la Prairie, Manitoba, à la Chambre des Communes (1908-1921). Solliciteur général (1913-1917), secrétaire d’État (1917), ministre de l'Intérieur (1917-1920); surintendant des Affaires indiennes (1917-1920) et ministre des Mines (1919-1920) dans le cabinet Borden. Premier ministre unioniste et ministre des Affaires extérieures (1920-1921); nommé membre du Conseil privé de l'Empire britannique en 1920. Défait dans sa circonscription de Portage la Prairie lors de l'élection de 1921, il est élu député conservateur du comté de Grenville, Ontario, lors d'une élection complémentaire en 1922. Chef de l'opposition (1922-1925); de nouveau député de Portage la Prairie (1925-1926), Premier ministre, ministre des Affaires extérieures et président du Conseil privé de juin à septembre 1926, il quittera temporairement la politique après la défaite de son gouvernement aux élections générales de 1926. Nommé séna- 
teur et ministre sans portefeuille par R.B. Bennett en 1932, il restera ministre de 1932 à 1935 dans le cabinet Bennett. Leader du gouvernement au Sénat (1932-1935), il siégera dans la chambre haute pendant neuf ans avant de démissionner pour redevenir chef du Parti conservateur (1941-1942). Défait par un candidat de la CCF lors d'une élection partielle dans le comté ontarien de York-Sud (1942) que le Parti libéral ne contestera pas ouvertement. Humilié par cette défaite, Meighen quittera définitivement la politique active.

${ }^{18}$ Ici, il est fort possible que Bourassa fasse référence à l'éducation dans un sens extrascolaire, c'est-à-dire de l'éducation entendue commé étant l'ensemble des connaissances intellectuelles d'un individu. La Vergne avait fait ses études classiques au Séminaire de Québec avant d'être licencié en droit de l'Université Laval. Bourassa, pour sa part, ne détenait aucun diplôme classique ou universitaire. Pendant deux ans (1882-1883), il avait fait des études secondaires auprès d'un précepteur venu de France. En 1885, il entra à l'École polytechnique de Montréal, puis, l'année suivante, au Collège Holy Cross de Worcester, Massachusetts. Malade, il dut quitter ce collège en 1887. Lionel Groulx, dans ses Mémoires, affirme néanmoins que La Vergne était comoins cérébral, moins instruit, moins cultivé que Bourassa». [Groulx, Mes mémoires, Tome 3, op. cit., p. 190.] 